\title{
MANIFESTAÇÕES PATOLÓGICAS EM VIADUTOS DE CONCRETO ESTRUTURAL: ESTUDO DE CASO EM BRASÍLIA/DF
}

\section{PATHOLOGICAL MANIFESTATIONS IN STRUCTURAL CONCRETE VIADUCTS:}

A CASE STUDY IN BRASÍLIA / DF

Henrique Jorge Nery de Lima' Gustavo Henrique Barto Borges 2 Matheus Dourado Godoy ${ }^{3}$ Rodolfo de Azevedo Palhares ${ }^{4}$

\section{RESUMO}

O trabalho apresenta o estudo de caso de manifestações patológicas em viadutos de concreto estrutural por meio da metodologia GDE/UnB, que qualifica e quantifica a degradação de danos estruturais. A partir das informações obtidas por meio de vistorias e do uso da metodologia GDE/UNB foi realizada a caracterização do estado geral da estrutura com a finalidade de servir de subsídio para tomadas de decisões quanto a intervenções rotineiras, de forma a aumentar a vida útil dos elementos e família de elementos da estrutura. A rotina da metodologia consistiuse na definição das estruturas que foram escopo do estudo de caso; realização de inspeções em campo destas estruturas; catálogo das manifestações patológicas da estrutura por meio do levantamento fotográfico; caracterização das patologias, classificação segundo os fatores de ponderação e fatores de intensidade de danos da estrutura conforme a metodologia GDE/UnB para obras de arte especiais; cálculo e classificação global dos danos da estrutura. Concluindo-se que a maioria dos viadutos se encontram em um estado de degradação elevado.

Palavras-chave: Manifestações patológicas. Viaduto. GDE.

\section{ABSTRACT}

The paper presents the case study of pathological manifestations in structural concrete viaducts through the GDE / UnB methodology, which qualifies and quantifies the degradation of structural damages. Based on the information obtained

1 Doutorando em Estruturas e Construção Civil pela Universidade de Brasília (UNB). Docente do Centro Universitário do Distrito Federal (UDF). E-mail: hjnery@gmail.com 2 Graduado em Engenharia Civil pelo Centro Universitário do Distrito Federal (UDF). E-mail: gbartoborges@gmail.com

3 Graduado em Engenharia Civil pelo Centro Universitário do Distrito Federal (UDF).

E-mail: matheusdourado95@hotmail.com

4 Mestre em Estruturas e Construção Civil pela Universidade de Brasília (UNB).

Docente da Universidade Federal de Juiz de Fora (UFJF). E-mail: rodolfo.palhares@hotmail.com 
from local surveys and the use of the GDE / UNB methodology, the general state of the structure was characterized in order to serve as a subsidy for decision-making regarding routine interventions in order to extend the useful life of the elements and family of structure elements. The routine of the methodology consisted of defining the structures that were the scope of the case study; conducting field inspections of these structures; catalog of the pathological manifestations of the structure through the photographic survey; characterization of pathologies and classification according to the weighting factors and damage intensity factors of the structure according to the GDE / UnB methodology for special works of art; calculation and overall classification of the structure damage.

Keywords: Pathological manifestations. Viaduct. GDE.

\section{INTRODUÇÃO}

As estruturas apresentam uma tendência natural de degradação que se classificam em três níveis:

- Degradação dos elementos das estruturas.

- Transtorno dos usuários da utilização.

- Inviabilidade econômica.

No Brasil, os estudos sobre deterioração da estrutura ganham cada vez mais destaque. Com a necessidade desses estudos, se desenvolveu uma área da engenharia civil chamada de "Patologia das construções".

É chamado de patologia das construções o campo da engenharia civil responsável por estudar origens, formas de manifestação, consequências e degradação das estruturas. Segundo Souza e Ripper (1988), a patologia é muito mais que reconhecer anomalias em uma estrutura, é sobre o projeto e sua concepção estrutural, e em sua base, sobre a formação do engenheiro civil, já que a vida útil se tornou um dado fundamental para a concepção de projetos.

Devido ao incidente do viaduto que desabou na área central de Brasília no eixão sul próximo à galeria dos estados, notou-se a necessidade da definição do nível de degradação das obras de artes especiais. Com a definição do nível de degradação é possível estabelecer o estado de deterioração da estrutura estudada em: baixo, médio, alto, sofrível e crítico, com o objetivo de criar um plano de ações.

Esta pesquisa tem a intenção de analisar a conservação e vida útil dos viadutos do eixo w sul de Brasília, que são um total de 8 viadutos, através de inspeções visuais realizadas nos viadutos em conjunto com ensaio fotográfico, 
definir sua intensidade e sua relevância na estrutura. Utilizando essas avaliações e inspeções, será definido um nível de degradação dos viadutos.

\section{CONCEITOS BÁSICOS}

Com a necessidade crescente em desenvolver um método que não dependesse totalmente do método empírico, Castro (1994), desenvolveu o método grau de deterioração da estrutura na universidade de Brasília, o qual mais tarde foi aperfeiçoado por diversos autores como: Fonseca (2007) o qual propôs alterações na formulação para o cálculo do grau de deterioração de uma família $\left(G_{\mathrm{df}}\right)$ e do Grau do Dano (D). Verly (2015) propôs alterações na formulação da metodologia GDE/ UnB para uma melhor aplicação a obras de arte especiais e constata que através dos diferentes danos nas estruturas inspecionadas, novamente conclui-se que a metodologia GDE/UnB apresentou resultados em escala de valores que facilitavam a priorização das estruturas quanto à tomada de decisão para intervenções.

O método apresentado pela Castro (1994) consiste em verificações periódicas a estrutura, dividindo-a em grupos para que se facilite a determinação da deterioração. Os aspectos mais avaliados são: segurança, funcionalidade e estética.

\section{METODOLOGIA GDE}

O uso da metodologia GDE/UnB é adequado para o uso das manifestações patológicas, uma vez que torna possível uma comparação de forma rápida e objetiva do nível de degradação da estrutura estudada, por meio de dados coletados em campo. A seguir, na figura é apresentado um fluxograma para uma melhor compreensão da metodologia. 
Figura 1: Fluxograma.

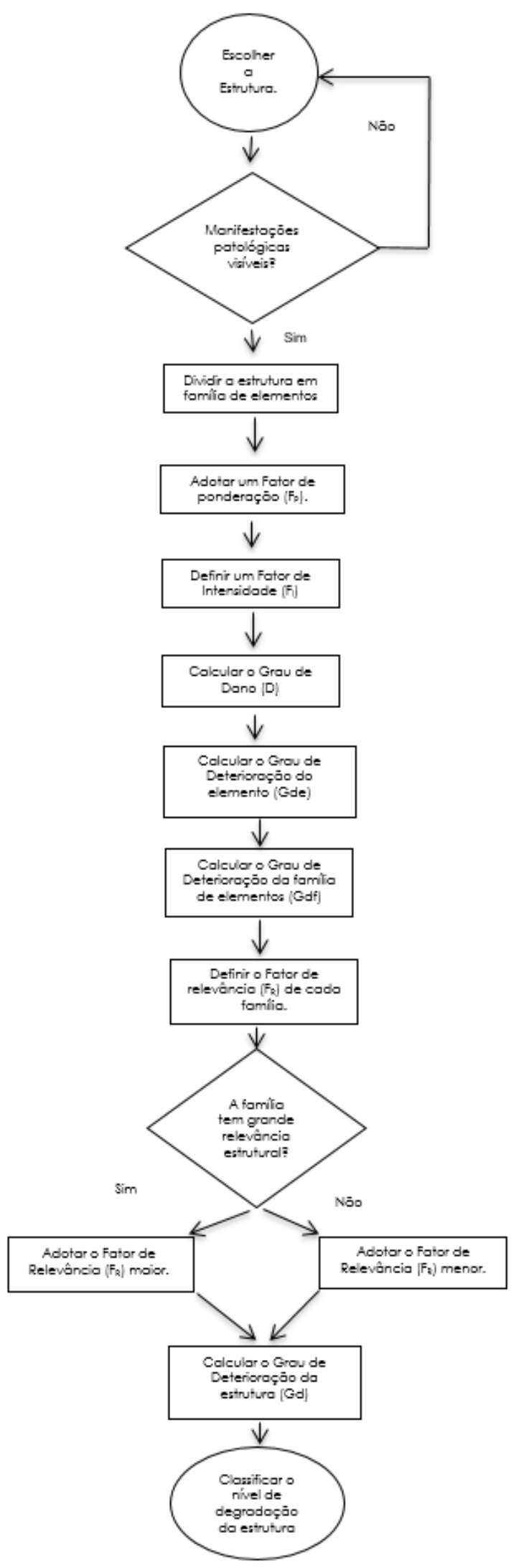

Fonte: Autor

\section{INTER/SCIENTIA}

REVISTA INTERSCIENTIA | V. 7 | N. 1 | P. 2-26 | JAN-JUN/2019 
Conforme o estudo da Castro (1994), a obra de arte estudada deve ser dividida em "famílias" de elementos estruturais típicos. Para cada elemento pertencente à família com o respectivo "fator de ponderação de dano", e para a determinação da gravidade de uma determinada manifestação patológica em seu elemento, é adotado um "fator de intensidade de dano", através do qual pode-se determinar a evolução da deterioração. Dessa forma, os fatores de danos são comuns para a família de elementos, enquanto os fatores de intensidade vão variar de acordo com a magnitude do dano em cada elemento da família.

Posteriormente ao levantamento de dados em campo, determina-se para cada elemento de uma família, um "grau de deterioração" individual e na sequência o "grau de deterioração da família". Depois da determinação do grau de deterioração das diversas famílias que compõem a estrutura, adota-se um "fator de relevância estrutural da família", o qual estabelecido conforme a importância relativa na finalidade e na segurança estrutural. E finalmente através de uma fórmula matemática (expressão 5), se obtêm o "grau de deterioração da estrutura".

\section{CLASSIFICAÇÃO DAS FAMÍLIAS DE ELEMENTOS}

Segundo Castro (1994), as estruturas inspecionadas devem ser subdivididas conforme as características estruturais de seus elementos componentes em "famílias".

Para o trabalho apresentado foi empregado a seguinte divisão: vigas, lajes, guarda-corpo, pista de rolamento, juntas de dilatação e cortinas.

\section{FATOR DE PONDERAÇÃO DE DANO}

O fator de ponderação de dano $\left(F_{p}\right)$ é utilizado para mensurar a importância de um dano, no que se refere às condições de estética, finalidade e segurança dos elementos de uma família. Para a definição do fator é levado em consideração à família onde o elemento está inserido e a consequência que o dano pode trazer.

\section{FATOR DE INTENSIDADE DE DANO}

O fator de intensidade de dano $\left(F_{i}\right)$ é responsável por determinar o nível de gravidade e o desenvolvimento de uma manifestação de dano em um determinado elemento. Com a necessidade de uma classificação detalhada, Castro (1994), desenvolveu as classificações mostradas no Quadro 1: 
Quadro 1: Valores de fator de intensidade de dano, adaptado Fonseca (2007).

\begin{tabular}{|c|c|c|}
\hline $\begin{array}{l}\text { Manifestação } \\
\text { Patológica. }\end{array}$ & $\begin{array}{l}\text { Valores } \\
\text { de Fi }\end{array}$ & Descrição \\
\hline \multirow{4}{*}{ Flechas } & 1 & $\rightarrow$ não perceptíveis a olho nu. \\
\hline & 2 & $\rightarrow$ perceptíveis a olho nu, dentro dos limites previstos na norma. \\
\hline & 3 & $\rightarrow$ superiores em até $40 \%$ às previstas na norma. \\
\hline & 4 & $\rightarrow$ excessivas. \\
\hline \multirow{3}{*}{$\begin{array}{l}\text { Impermeabilização } \\
\text { deficiente }\end{array}$} & 2 & $\begin{array}{l}\rightarrow \text { danos na camada protetora e/ou perda de elasticidade do material da } \\
\text { impermeabilização. }\end{array}$ \\
\hline & 3 & $\rightarrow$ descontinuada, degradada em alguns pontos (pontos de infiltração). \\
\hline & 4 & $\rightarrow$ degradação acentuada, com perda relevante da estanqueidade. \\
\hline \multirow{4}{*}{ Infiltração de água } & 1 & $\rightarrow$ indícios de umidade. \\
\hline & 2 & $\rightarrow$ pequenas manchas. \\
\hline & 3 & $\rightarrow$ grandes manchas. \\
\hline & 4 & $\rightarrow$ generalizada. \\
\hline \multirow{3}{*}{ Manchas } & 2 & $\begin{array}{l}\rightarrow \text { manchas escuras de pouca extensão, mas significativas (< } 50 \% \text { da área visí- } \\
\text { vel do elemento estrutural). }\end{array}$ \\
\hline & 3 & $\rightarrow$ manchas escuras de grande extensão (>50\%). \\
\hline & 4 & $\rightarrow$ manchas escuras em todo o elemento estrutural (100\%). \\
\hline \multirow{3}{*}{$\begin{array}{l}\text { Obstrução de juntas } \\
\text { de dilatação }\end{array}$} & 2 & $\begin{array}{l}\rightarrow \text { perda de elasticidade do material da junta; início de fissuras paralelas às } \\
\text { juntas nas lajes e paredes adjacentes. }\end{array}$ \\
\hline & 3 & $\begin{array}{l}\rightarrow \text { presença de material não compressível na junta; incidência significativa de } \\
\text { fissuras paralelas às juntas nas lajes e paredes adjacentes. }\end{array}$ \\
\hline & 4 & $\begin{array}{l}\rightarrow \text { fissuras em lajes e paredes adjacentes às juntas, com prolongamento em } \\
\text { vigas e/ou pilares de suporte. }\end{array}$ \\
\hline \multirow{3}{*}{ Recalques } & 2 & $\rightarrow$ indícios de recalque pelas características das trincas na alvenaria; \\
\hline & 3 & $\rightarrow$ recalque estabilizado com fissuras em peças estruturais. \\
\hline & 4 & $\rightarrow$ recalque não estabilizado com fissuras em peças estruturais. \\
\hline
\end{tabular}

\section{GRAU DE DANO}

O grau de dano (D) tem como propósito mensurar cada dano no elemento. O qual depende do fator de ponderação $\left(F_{p}\right)$ e o fator de intensidade $\left(F_{i}\right) . O$ grau de dano é obtido através das expressões (1)-(2).

$$
\begin{array}{ll}
\boldsymbol{D}=\mathbf{0 , 8} \times \boldsymbol{F}_{i} \times \boldsymbol{F}_{\boldsymbol{p}} & \text { Para } \mathrm{F}_{\mathrm{i}} \leq 2 \\
\boldsymbol{D}=\left(\mathbf{1 2} \times \boldsymbol{F}_{\boldsymbol{i}}-\mathbf{2 8}\right) \times \boldsymbol{F}_{\boldsymbol{p}} & \text { Para } \mathrm{F}_{\mathrm{i}} \geq 3
\end{array}
$$

\section{GRAU DE DETERIORAÇÃO DE UM ELEMENTO}

O grau de deterioração de um elemento $\left(G_{\text {de }}\right)$ estrutural isolado indica o grau de dano máximo de um elemento, em atribuição das manifestações dos danos detectados na inspeção. Através da expressão (3) e possível encontrar o $G_{\text {de }}$. 


$$
G_{d e}=D_{m a ́ x}\left[1+\frac{\sum_{i=1}^{m} D(i)-D_{m i x}}{\sum_{i=1}^{m} D(i)}\right]
$$

Onde: $\mathrm{D}_{\text {máx }}=$ Grau máximo de dano em um elemento $D_{i}=$ Grau de dano ordem i

\section{GRAU DE DETERIORAÇÃO DE UMA FAMÍLIA DE ELEMENTOS}

O grau de deterioração de uma família $\left(G_{d f}\right)$, segundo Verly $(2015)$ tem como objetivo avaliar os elementos pertencentes a uma família. O qual leva em conta os de $G_{\text {de }} \geq 15$, de cada elemento pertencente à família. E utilizado a expressão (4) para determinar o grau de deterioração da família.

$$
G_{d f}=G_{\text {demáx }}\left[\sqrt{1+\frac{\sum_{i=1}^{m} G_{d e}(i)-G_{\text {demax }}}{\sum_{i=1}^{m} G_{d e}(i)}}\right]
$$

\section{FATOR DE RELEVÂNCIA ESTRUTURAL DA FAMÍLIA DE ELEMENTOS}

Segundo Verly (2015), o fator de relevância estrutural da família de elementos $\left(F_{r}\right)$ consiste em considerar a importância equivalente das diversas famílias de elementos para cada família que a obra foi dividida, assim, o fator depende da tipologia da estrutura. Visando um melhor resultado serão usados os fatores de relevância apresentados no quadro 2 a seguir.

Quadro 2: Fator de relevância estrutural das famílias de elementos.

\begin{tabular}{|l|c|}
\hline Família & Fr \\
\hline Barreiras, guarda-corpo, guarda rodas, pista de rolamento & 1 \\
\hline Juntas de dilatação & 2 \\
\hline Transversinas, cortinas, alas & 3 \\
\hline Lajes, fundações, vigas secundárias, aparelhos de apoio & 4 \\
\hline Vigas e pilares principais & 5 \\
\hline
\end{tabular}

\section{GRAU DE DETERIORAÇÃO DA ESTRUTURA}

O grau de deterioração da estrutura $\left(G_{d}\right)$ é determinado em função dos valores de grau de deterioração da família $\left(G_{\mathrm{df}}\right)$ de cada família presente na estrutura e seus respectivos fatores de relevância $\left(F_{R}\right)$, a expressão (5) mostra como se obtém o $G_{d}$. 


$$
\boldsymbol{G}_{\boldsymbol{d}}=\frac{\sum_{i=1}^{m} \boldsymbol{F}_{r}(i) G_{d f}(i)}{\sum_{i=1}^{m} \boldsymbol{F}_{r}(i)}
$$

\section{CLASSIFICAÇÃO DA DETERIORAÇÃO}

Com o valor de $G_{d}$ obtido, pode-se classificar o nível de deterioração da estrutura, a qual indicara a condição atual da estrutura, visando às ações adequadas a serem tomadas em relação à estrutura estudada. Utilizando o quadro 3 a seguir, apresentado por Fonseca (2007), para assim definir ações recomendadas com base nos valores obtidos no grau de deterioração.

Quadro 3: Classificação da deterioração.

\begin{tabular}{|c|c|c|}
\hline Nível de deterioração & Gd & Ações recomendadas \\
\hline \multirow{2}{*}{ Baixo } & \multirow{2}{*}{$0-15$} & Estado aceitável. \\
\hline & & Manutenção preventiva. \\
\hline \multirow{2}{*}{ Médio } & \multirow{2}{*}{$15-50$} & Definir prazo e natureza de nova inspeção. \\
\hline & & Planejar intervenção em longo prazo (máximo 2 anos). \\
\hline \multirow{2}{*}{ Alto } & \multirow{2}{*}{$50-80$} & Definir prazo para inspeção especializada. \\
\hline & & Planejar intervenção em médio prazo (máximo 1 ano). \\
\hline \multirow{2}{*}{ Sofrível } & \multirow{2}{*}{$80-100$} & Definir prazo para inspeção especializada rigorosa. \\
\hline & & Planejar intervenção em curto prazo (máximo 6 meses). \\
\hline \multirow{2}{*}{ Crítico } & \multirow{2}{*}{$>100$} & $\begin{array}{l}\text { Inspeção especializada imediata e medidas emergenciais } \\
\text { (alívio de cargas, escoramento, etc.). }\end{array}$ \\
\hline & & Planejar intervenção imediata. \\
\hline
\end{tabular}

Fonte: Adaptado Fonseca (2007).

\section{ANÁLISE DOS VIADUTOS}

A análise dos viadutos foi realizada dia 02/09/2018, realizando inspeções visuais e fotografias das manifestações patológicas, sempre evitando comentários pessoais a fim de evitar diagnósticos falsos. A seguir uma breve descrição das manifestações encontradas.

\section{VIADUTO 01/02}

Na Figura 2 é mostrada uma vista frontal do viaduto, na Figura 3 é possível observar fendas abertas no guarda corpo, armaduras aparentes na parte inferior, desplacamento de parte do concreto e um pó de coloração branca que pode indicar o processo de carbonatação do concreto, todas essas manifestações podem ocasionar uma corrosão das armaduras de aço presentes na estrutura e na Figura 4 é possível observar o desgaste na junta de dilatação e descolamento de cerâmicos. Este viaduto está localizado próximo a SQS 102. 
Utilizando a metodologia GDE/UNB foi encontrado o valor 72,32 de $G_{d^{\prime}}$ que pela metodologia e definido como um nível de deterioração alto.

Figura 2: Vista frontal do viaduto

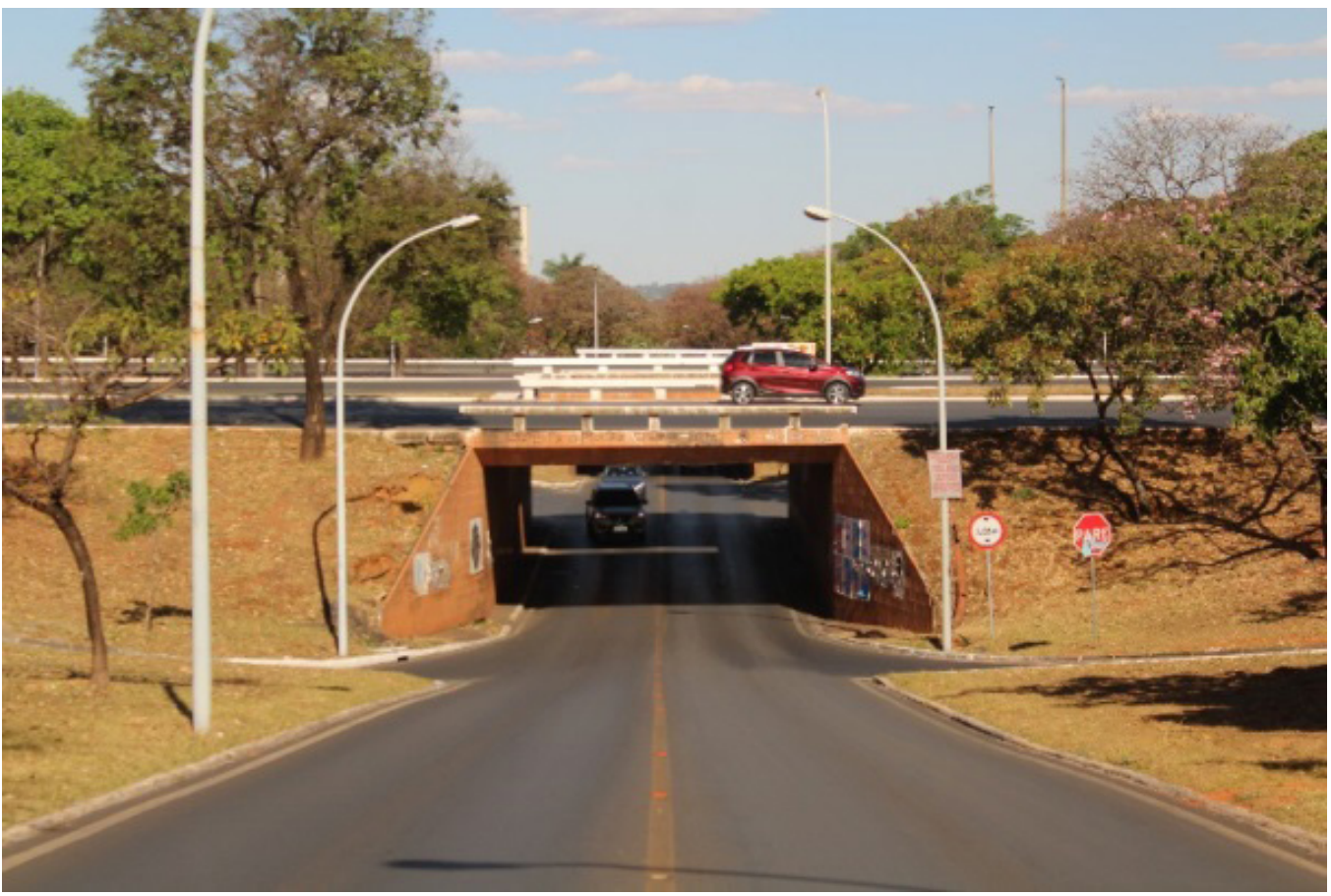

Fonte: Autor

Figura 3: Guarda corpo e parte superior central.

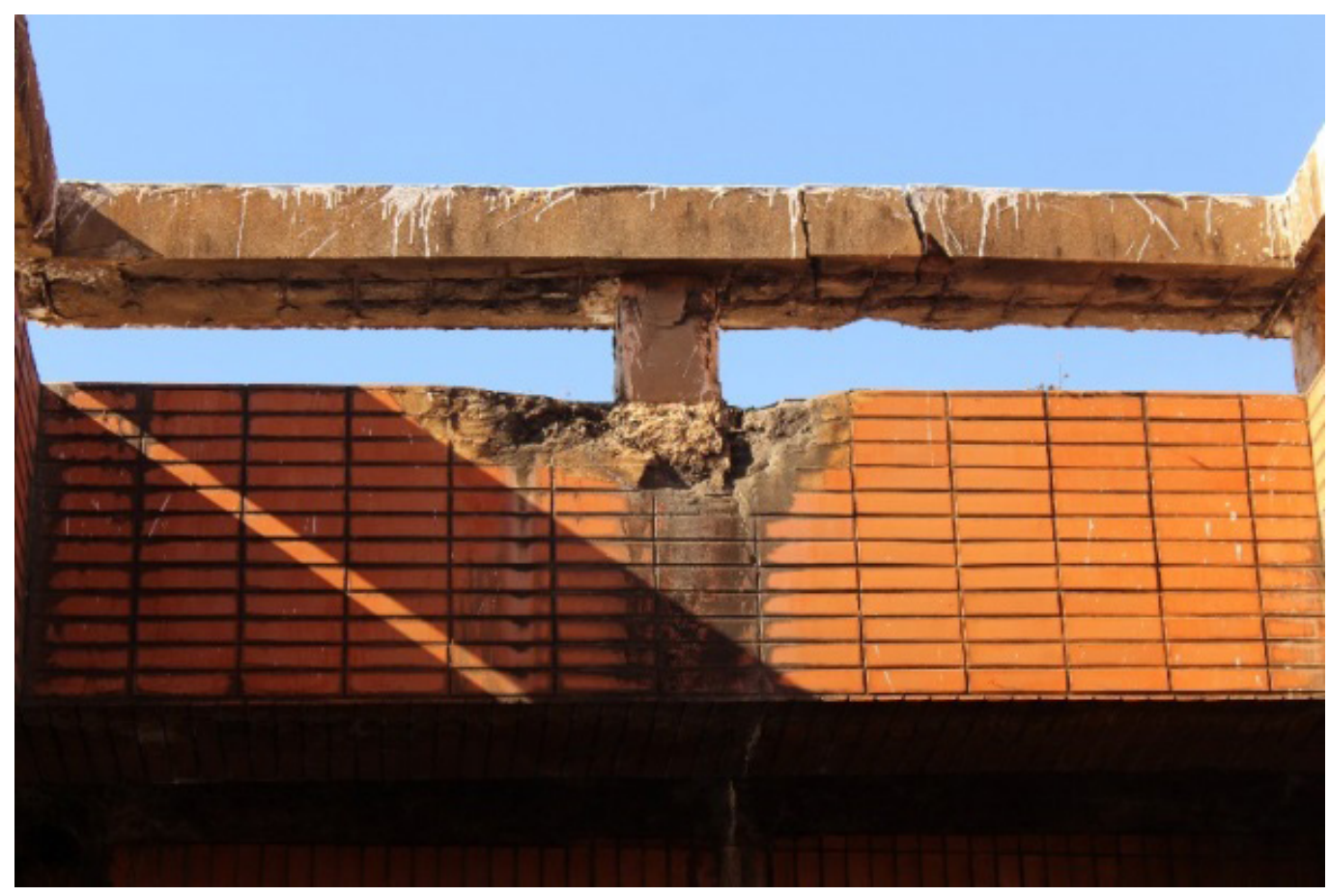

Fonte: Autor 
Figura 4: Junta de dilatação e cortina

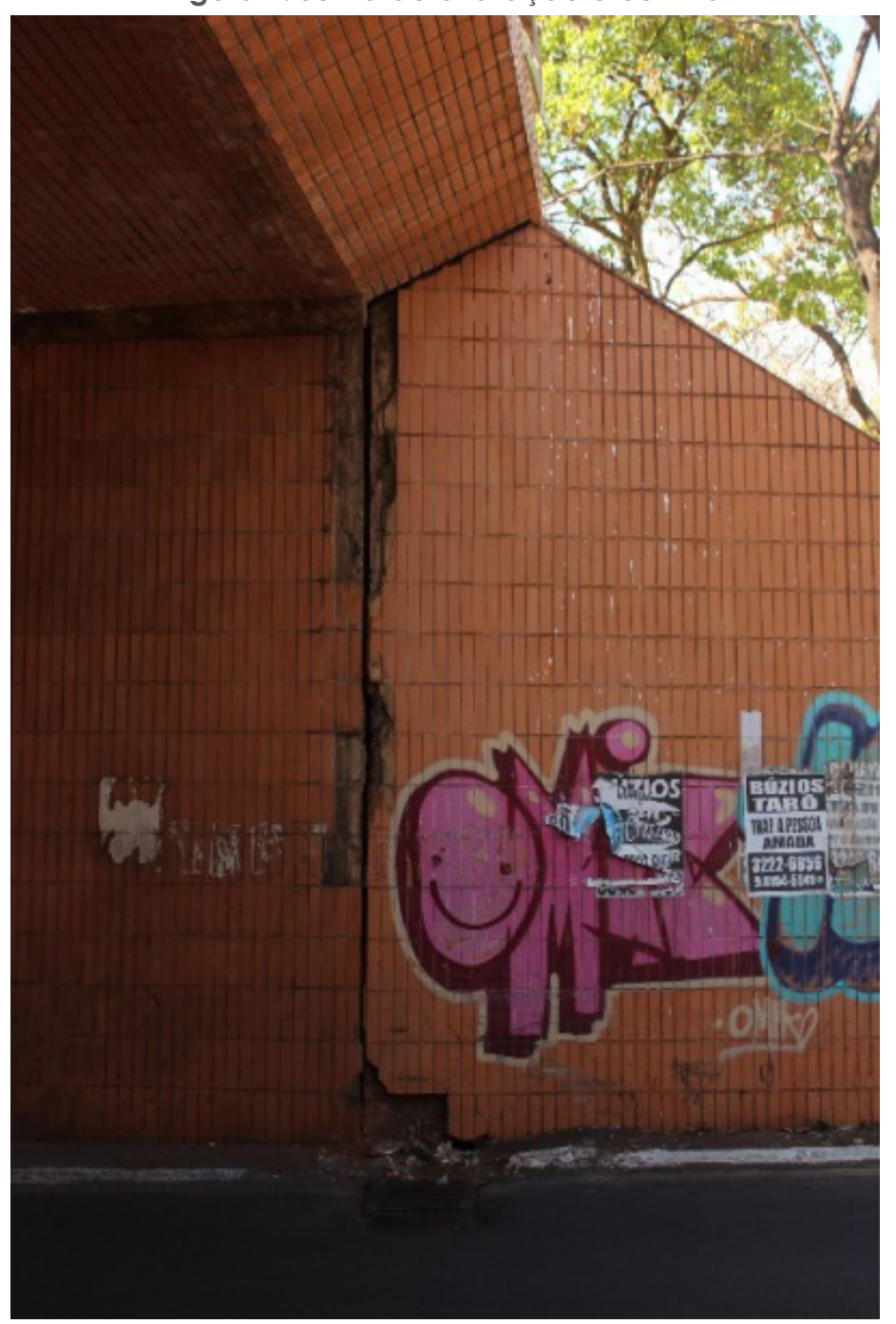

Fonte: Autor

\section{VIADUTO 03/04}

Na Figura 5 é mostrada uma vista frontal do viaduto, na Figura 6 é possível visualizar as armaduras devido à falta de cobrimento e efeitos que se assimilam a oxidação do concreto e da armadura, na Figura 7 é possível se ver o descolamento de cerâmicos e na Figura 8 observa-se uma fenda no guarda corpo. Este viaduto está localizado próximo a SQS 104.

Utilizando a metodologia GDE/UnB foi encontrado o valor 46,47 de $G_{d^{\prime}}$ que segundo a metodologia diz que o nível de deterioração é classificado como médio. 
Figura 5: Vista frontal do viaduto

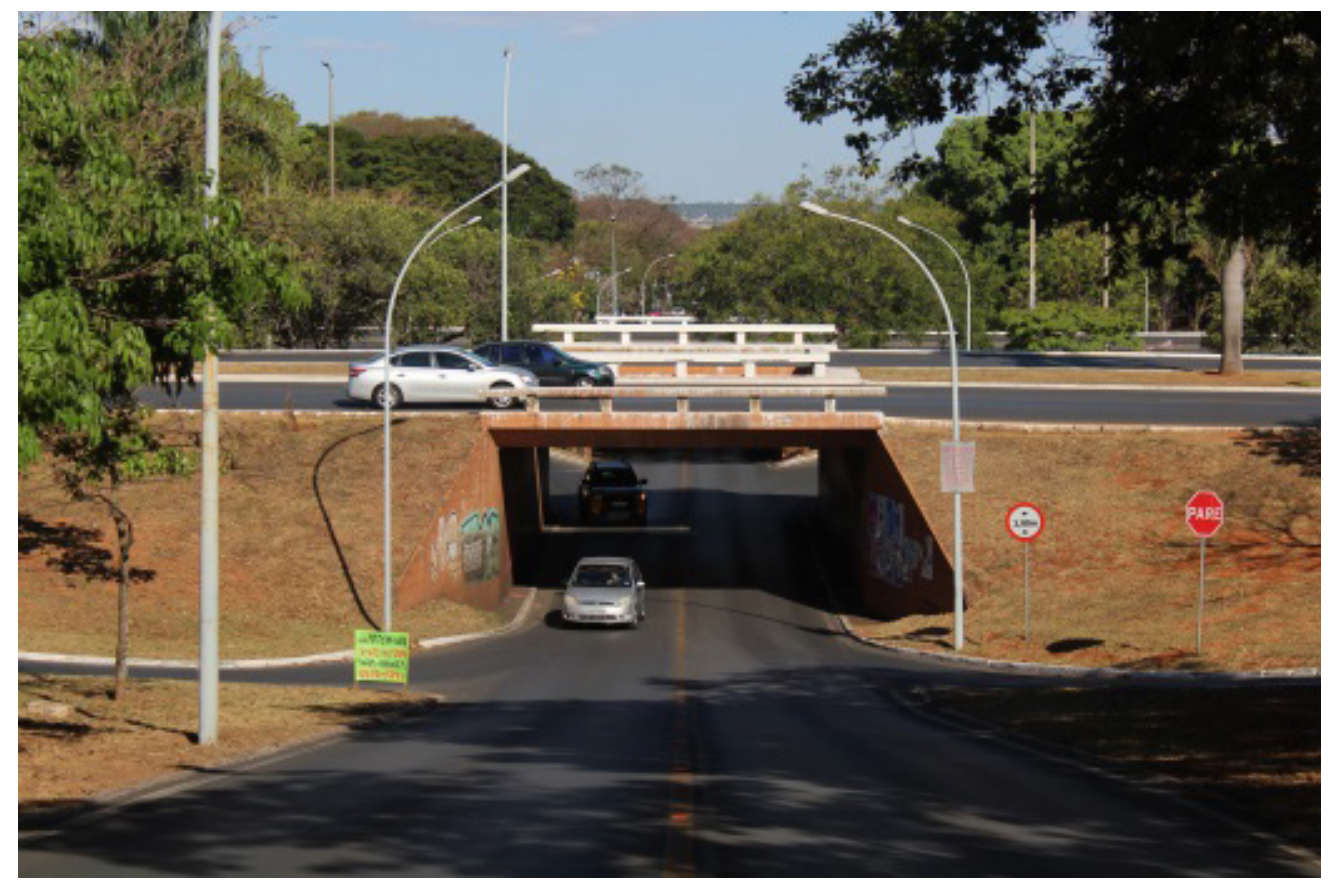

Fonte: Autor

Figura 6: Guarda corpo com armadura aparente.

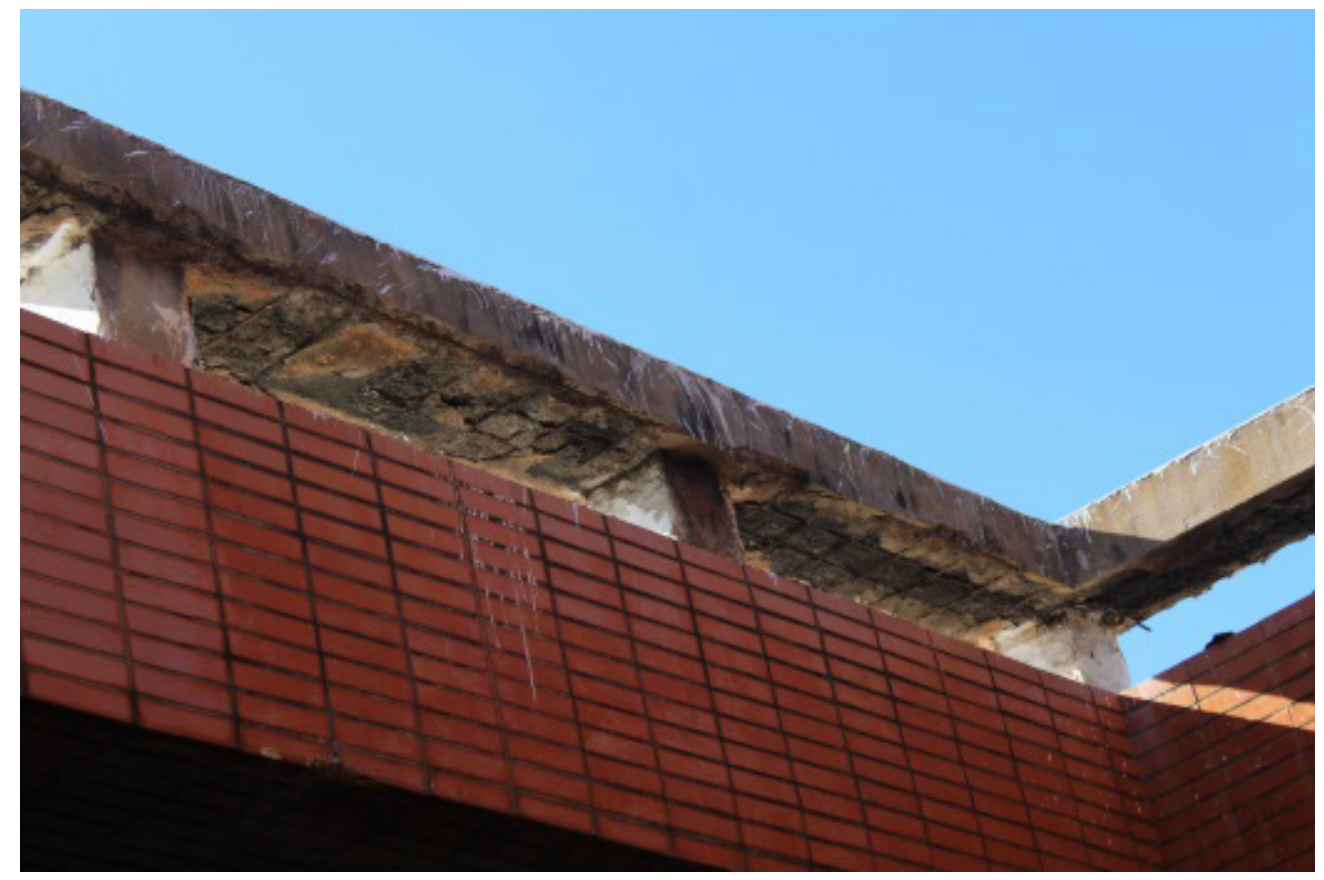

Fonte: Autor 
Figura 7: Descolamento de cerâmicos na laje.

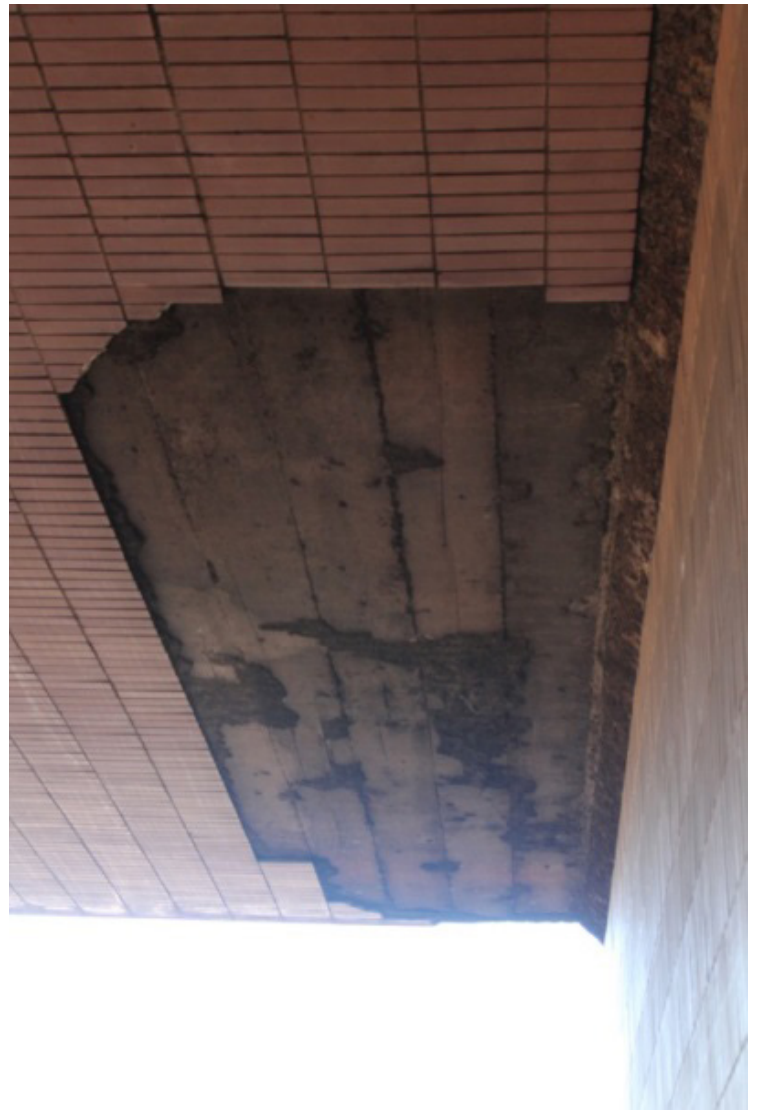

Fonte: Autor

Figura 8: Fenda no guarda-corpo.

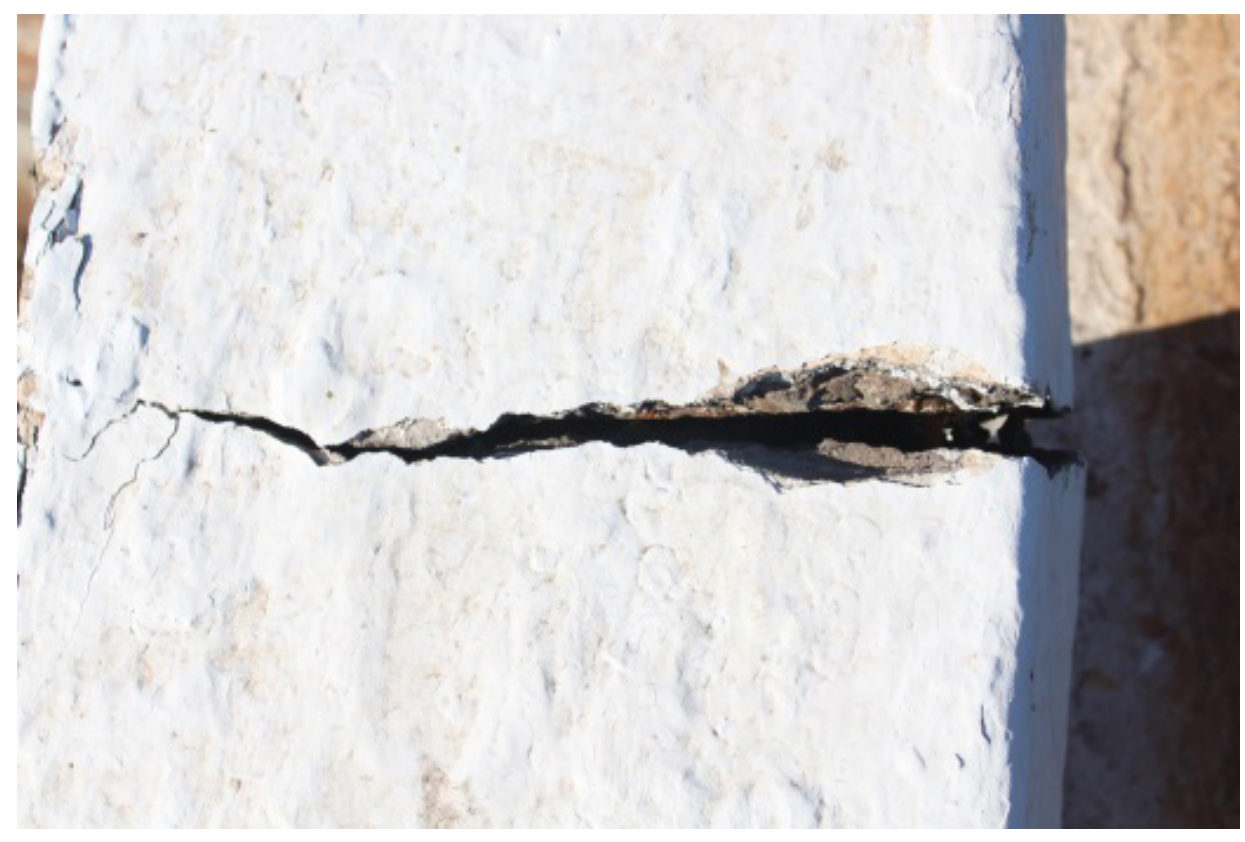

Fonte: Autor 


\section{VIADUTO 05/06}

Na Figura 9 é mostrada a vista frontal do viaduto, na Figura 10 observase um desplacamento e a armadura da cortina com manchas que indicam uma possível oxidação do concreto e na Figura 11 é mostrado o abaulamento da pista entorno de um bueiro. Este viaduto está localizado próximo a SQS 105.

Utilizando a metodologia GDE/UnB foi encontrado o valor 87,79 de $G_{d^{\prime}}$ que segundo a metodologia o nível de deterioração é classificado como sofrível.

Figura 9: Vista frontal do viaduto.

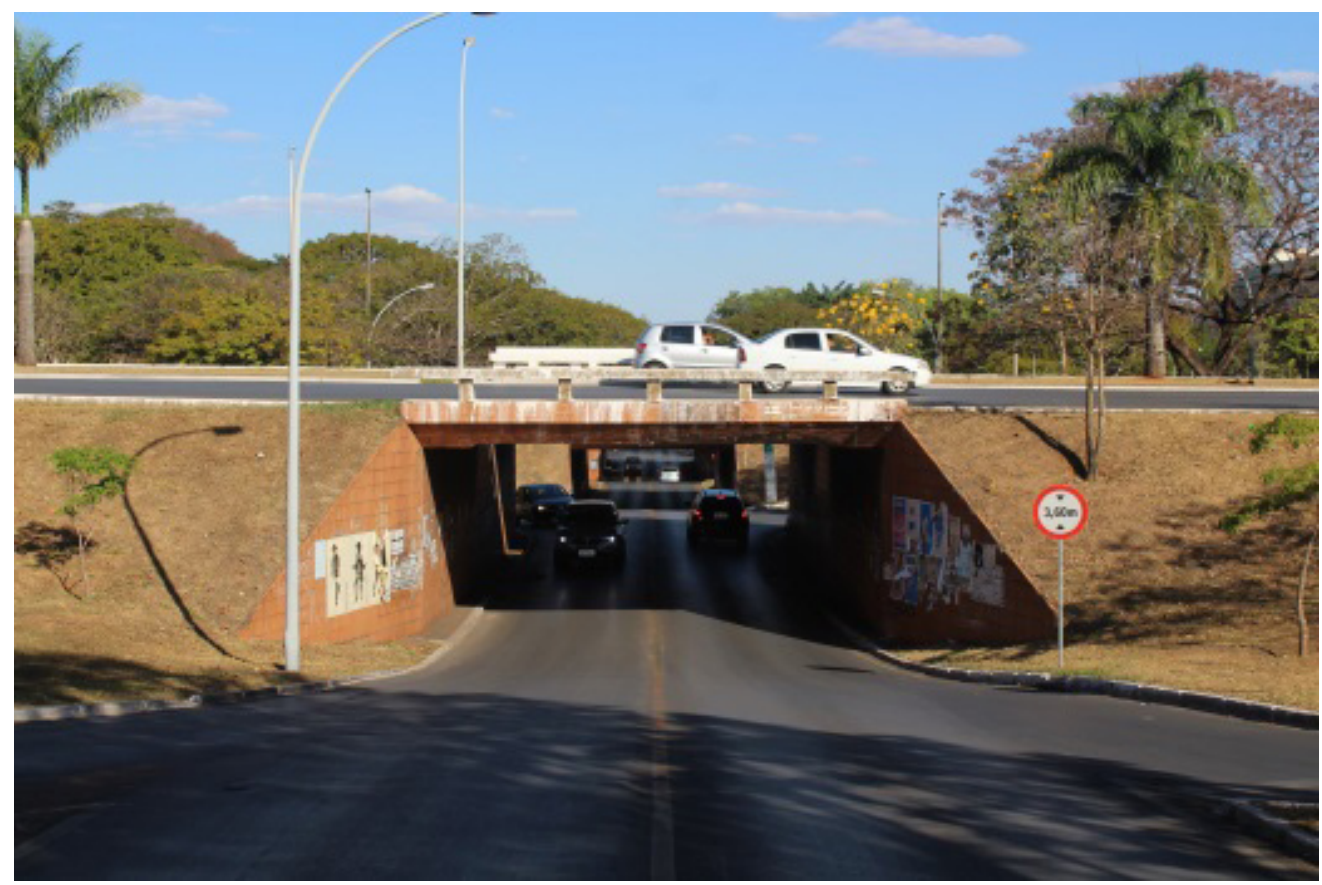

Fonte: Autor 
Figura 10: Desplacamento e manchas.

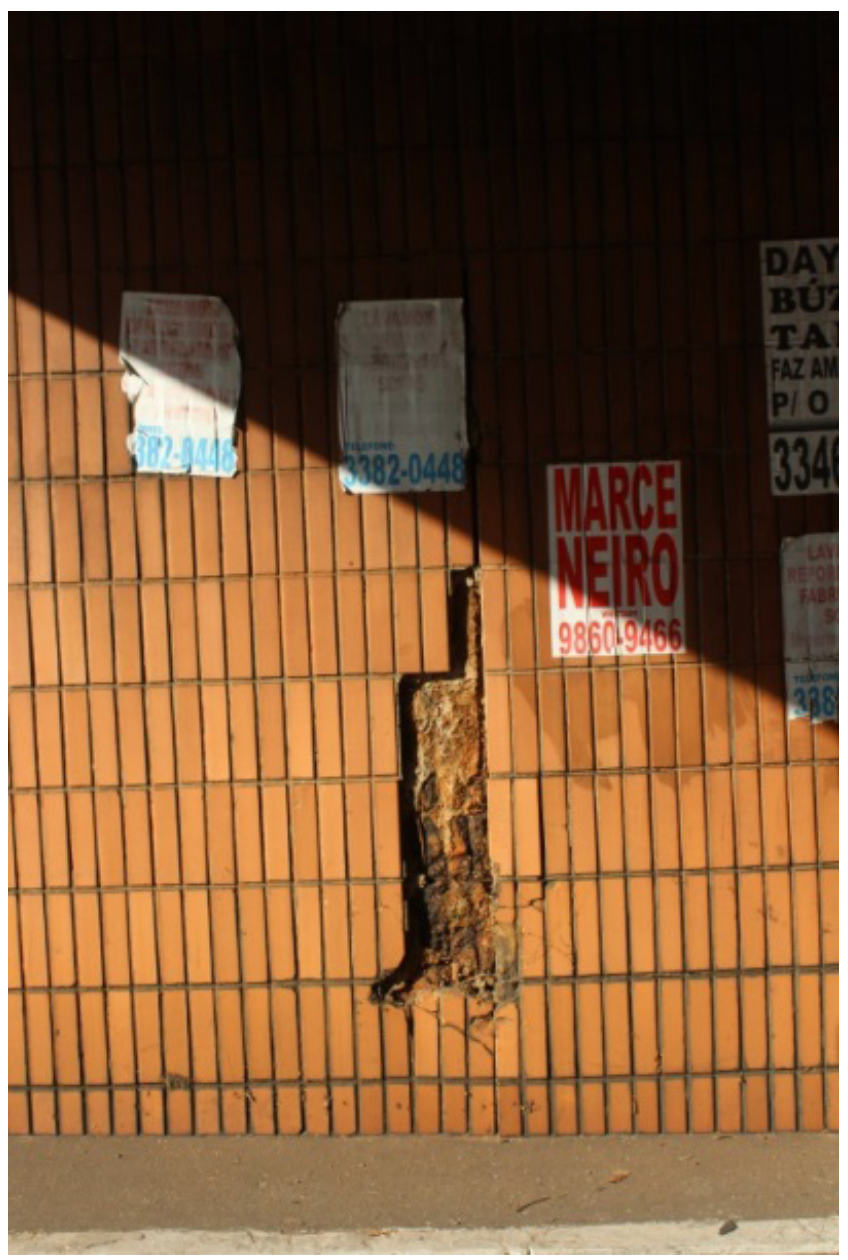

Fonte: Autor

Figura 11: Abaulamento próximo ao bueiro.

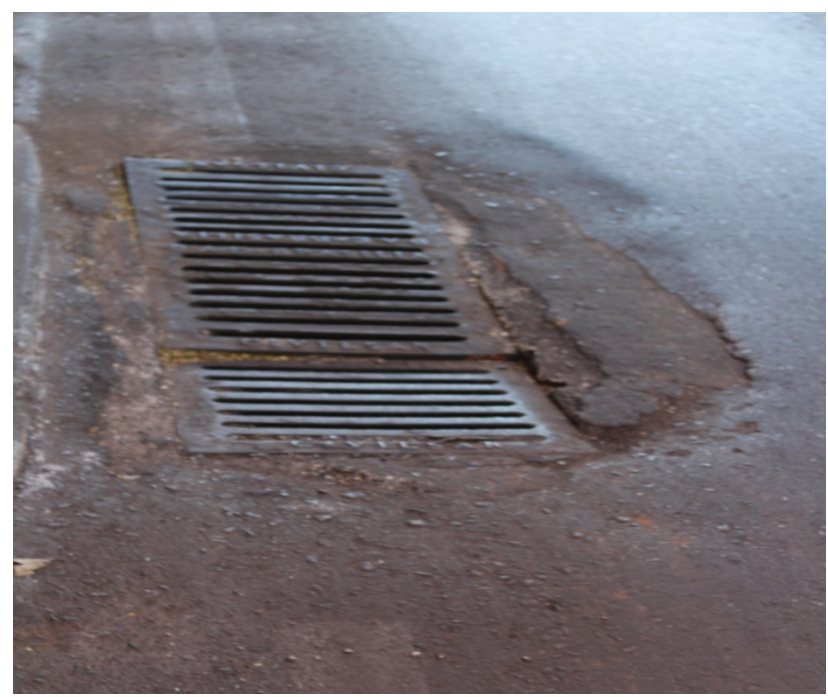

Fonte: Autor 


\section{VIADUTO 07/08}

Na figura 12 é mostrada a vista frontal do viaduto, na Figura 13 contém o desplacamento da laje e na Figura 14 é possível observar uma falha na continuidade da pista de rolamento. Este viaduto está localizado próximo a SQS 106.

Utilizando a metodologia GDE/UnB foi encontrado o valor 81,77 de $G_{d^{\prime}}$ que segundo a metodologia o nível de deterioração é classificado como sofrível.

Figura 12: Vista frontal do viaduto.

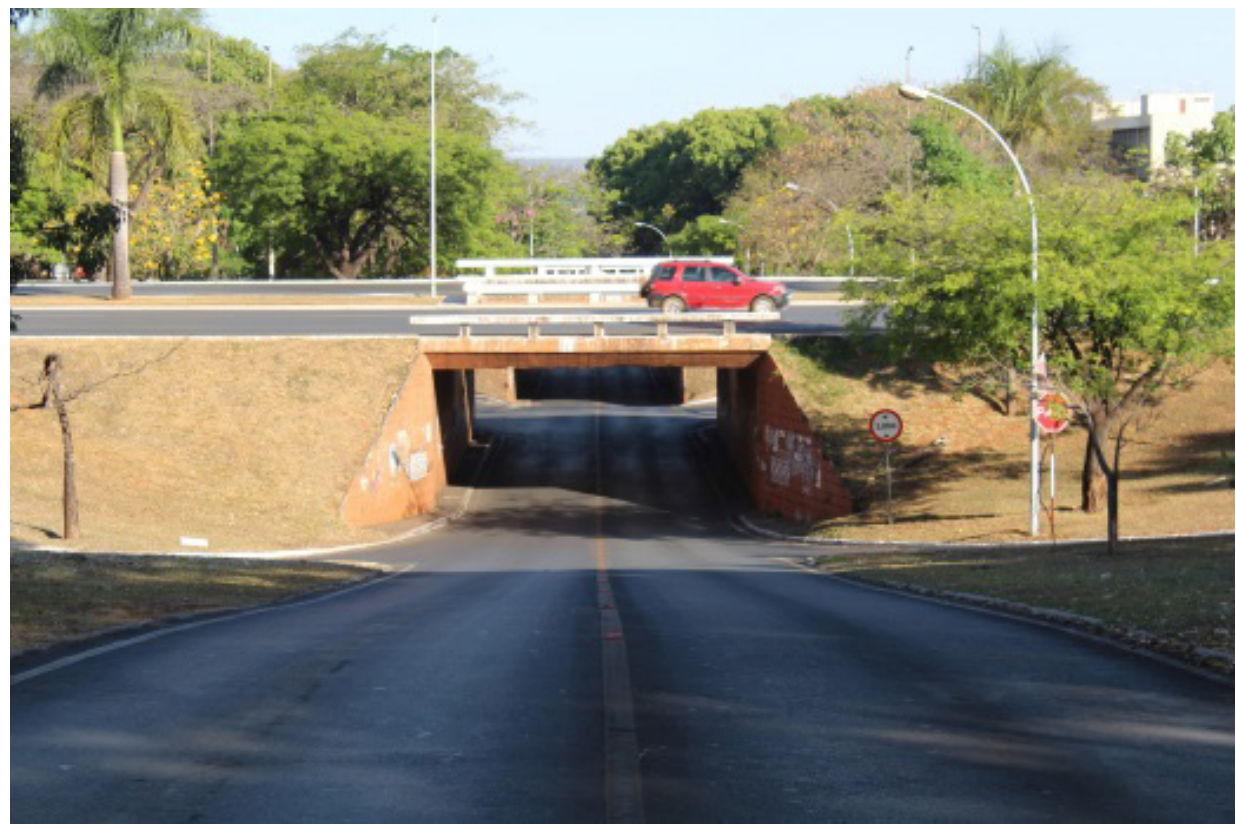

Fonte: Autor

Figura 13: Desplacamento da laje.

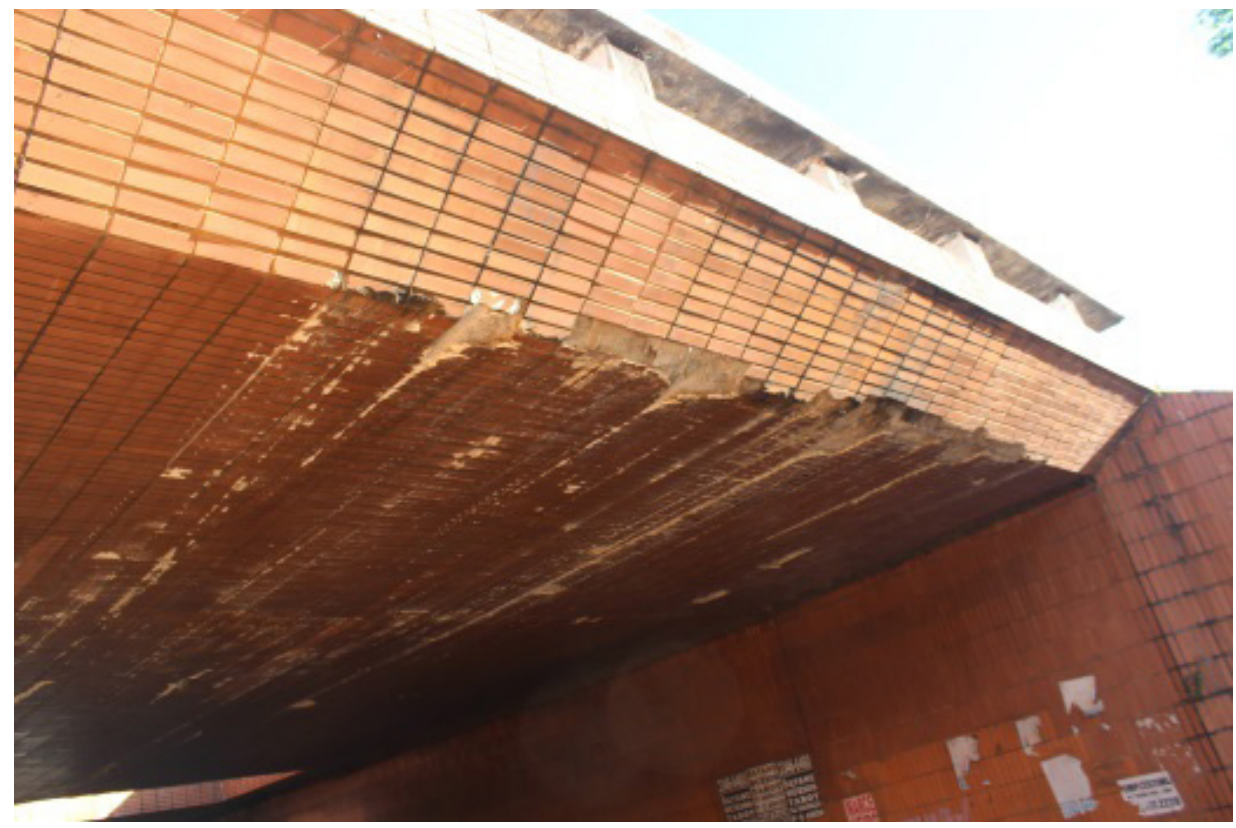

Fonte: Autor

\section{INTER SCIENTIA}

REVISTA INTERSCIENTIA | V. 7 | N. 1 | P. 2-26 | JAN-JUN/2019 
Figura 14: Descontinuidade no pavimento.

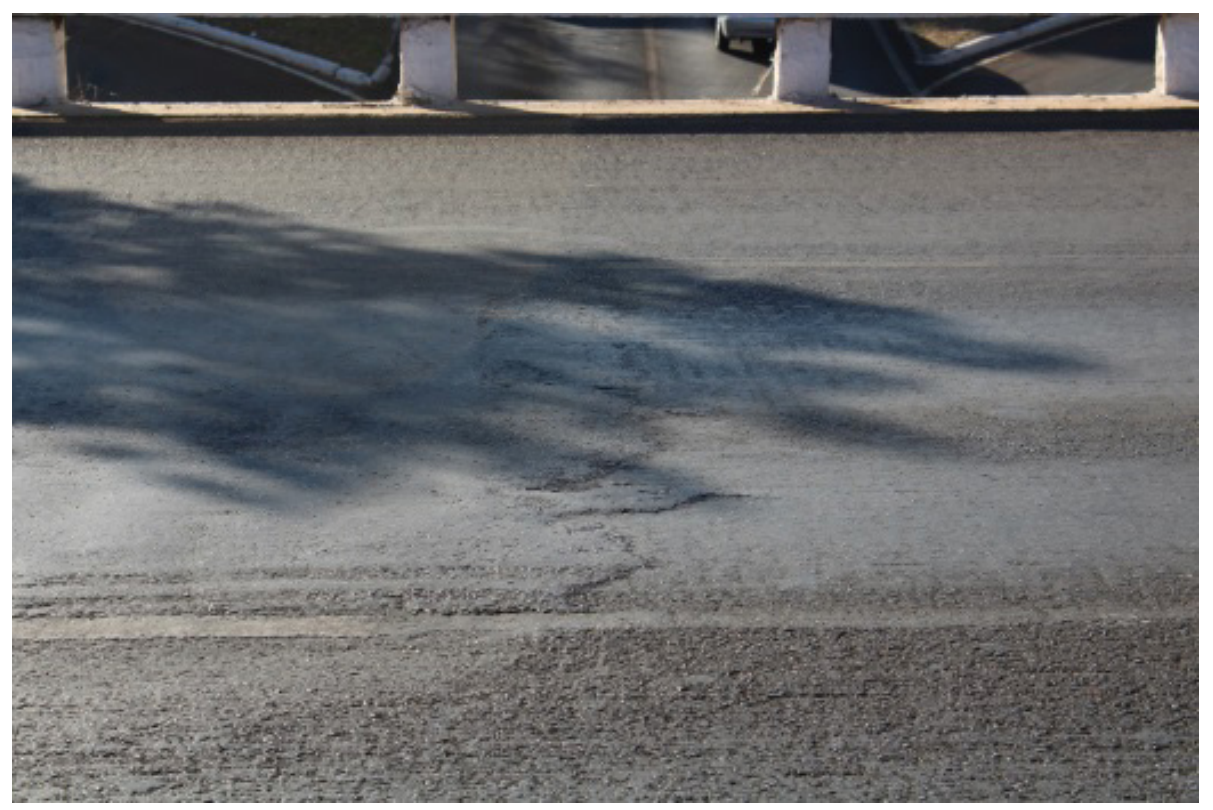

Fonte: Autor

\section{VIADUTO 09/10}

Na Figura 15 é mostrada a vista frontal do viaduto, na Figura 16 é possível ver o desgastamento do material da junta de dilatação. Este viaduto está localizado próximo a SQS 109.

Utilizando a metodologia GDE/UnB foi encontrado o valor 49,88 de $G_{d^{\prime}}$ que segundo a metodologia o nível de deterioração é classificado como médio.

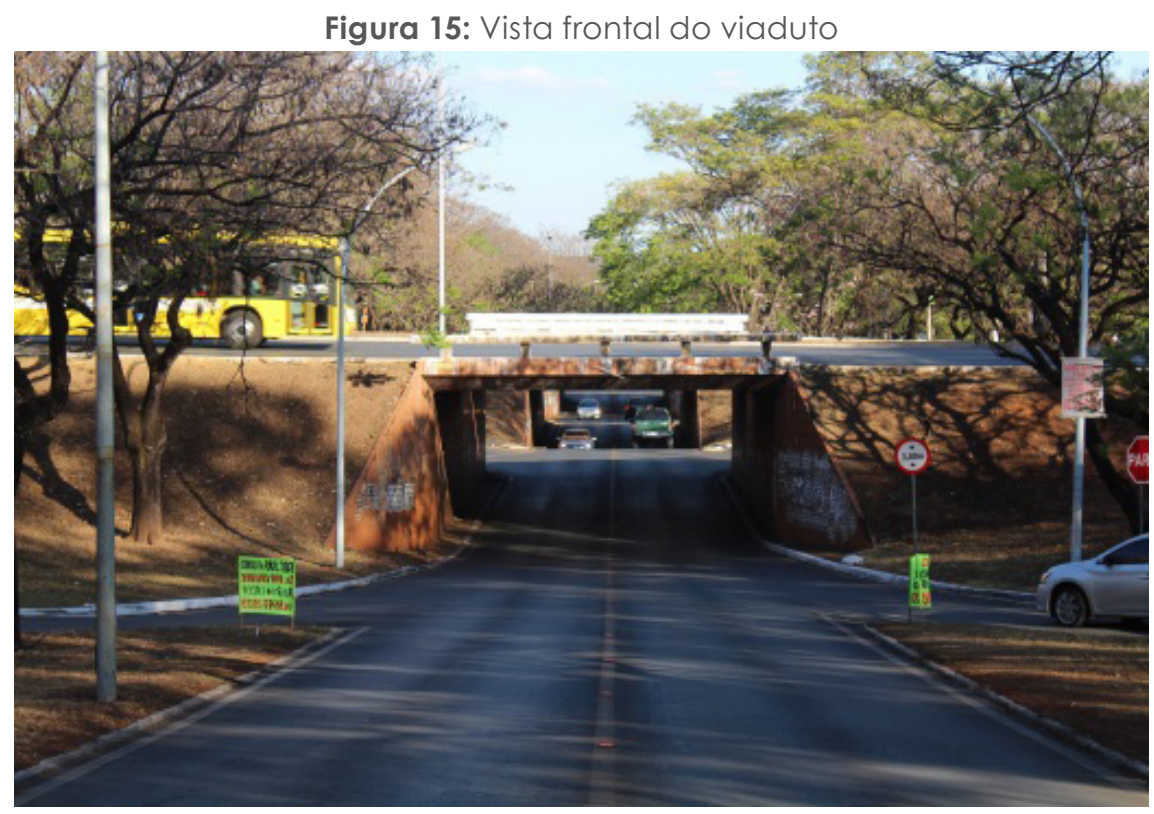

Fonte: Autor

\section{INTER/SCIENTIA}

REVISTA INTERSCIENTIA | V. 7 | N. 1 | P. 2-26 | JAN-JUN/2019

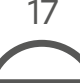


Figura 16: Desgaste da junta de dilatação.

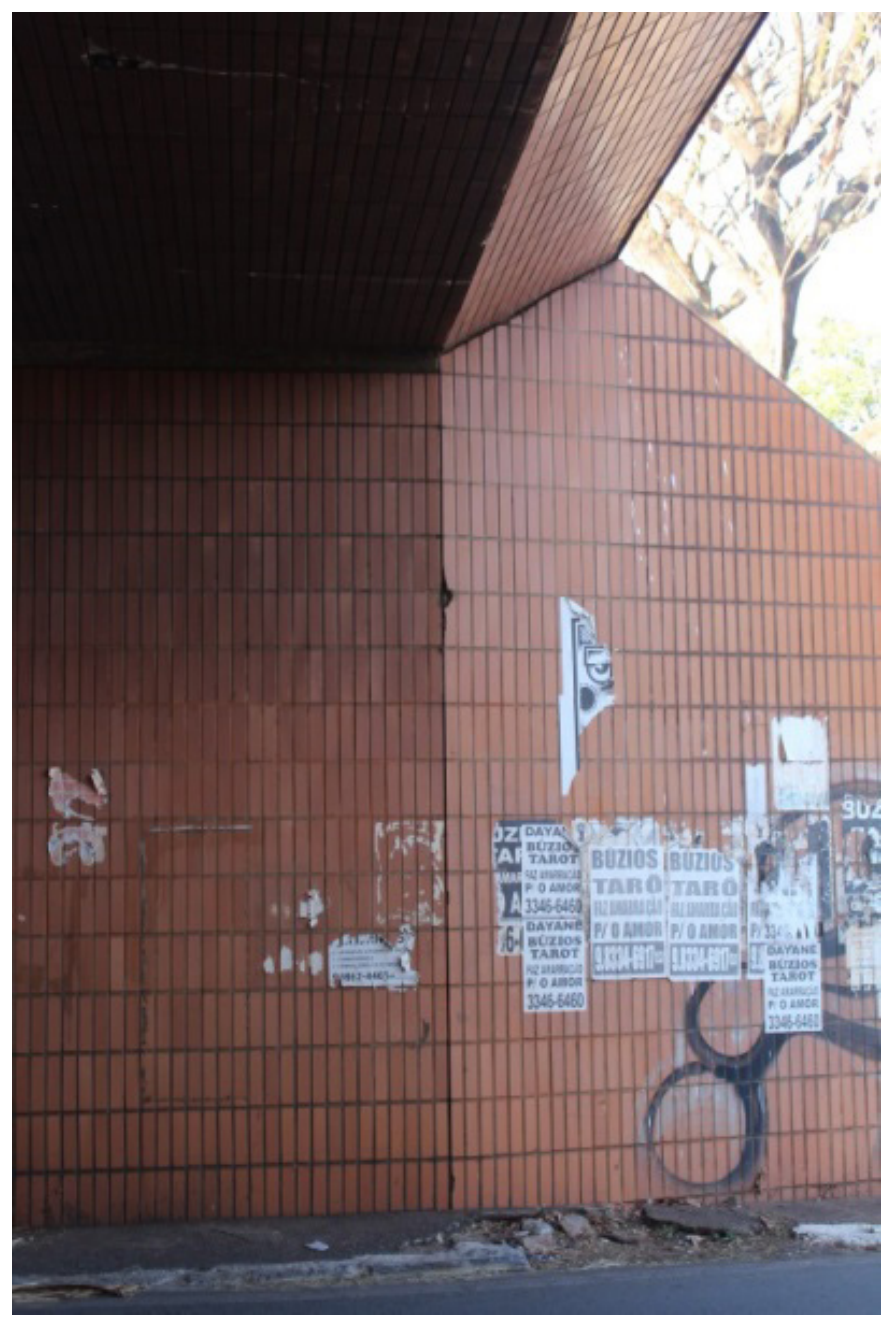

Fonte: Autor

\section{VIADUTO $11 / 12$}

Na Figura 17 é mostrada a vista frontal do viaduto, na Figura 18 é possível ver o desplacamento da cortina e o preenchimento parcial de concreto na junta de dilatação e na Figura 19, além do desplacamento e do desgaste da junta de dilatação observa-se armadura aparente. Este viaduto está localizado próximo SQS 111.

Utilizando a metodologia GDE/UnB foi encontrado o valor 97,34 de $G_{d^{\prime}}$ que segundo a metodologia o nível de deterioração é classificado como sofrível. 
Figura 17: Vista frontal do viaduto.

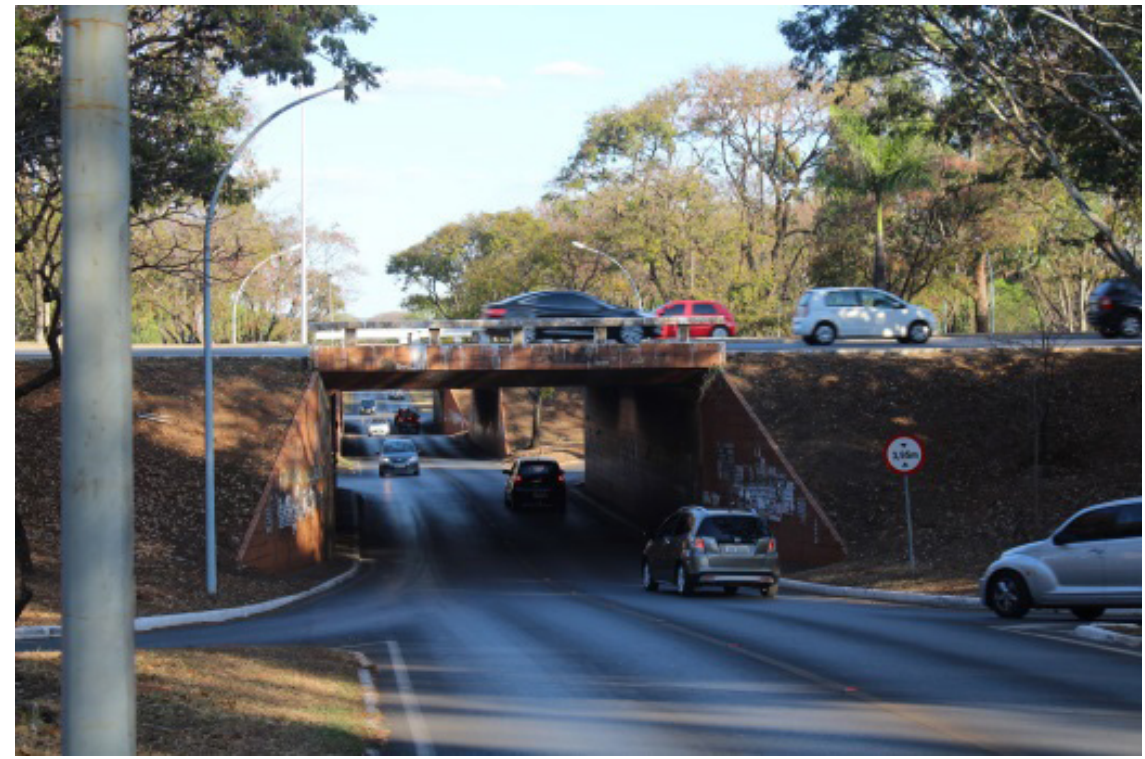

Fonte: Autor

Figura 18: Junta de dilatação e Cortina.

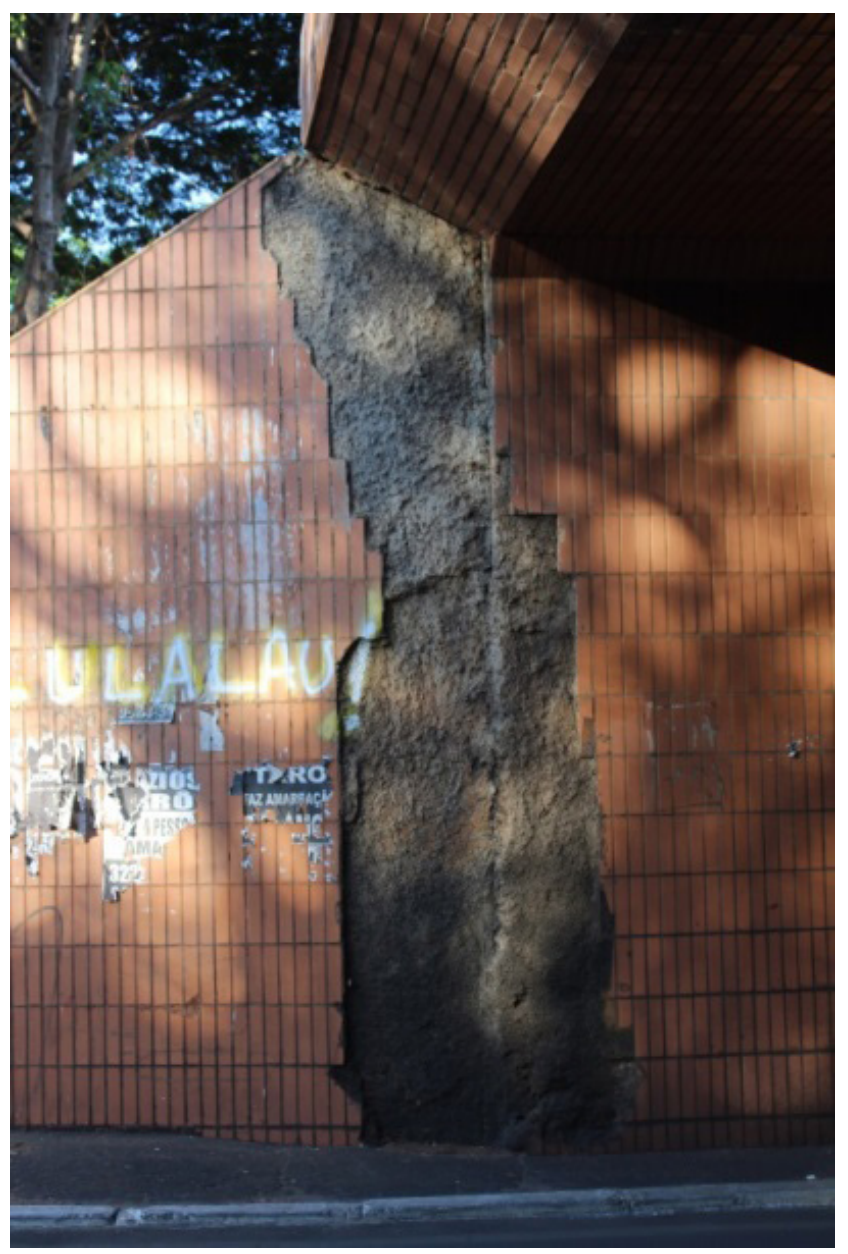

Fonte: Autor

INTER SCIENTIA

REVISTA INTERSCIENTIA | V. 7 | N. 1 | P. 2-26 | JAN-JUN/2019 
Figura 19: Junta de dilatação e Cortina.

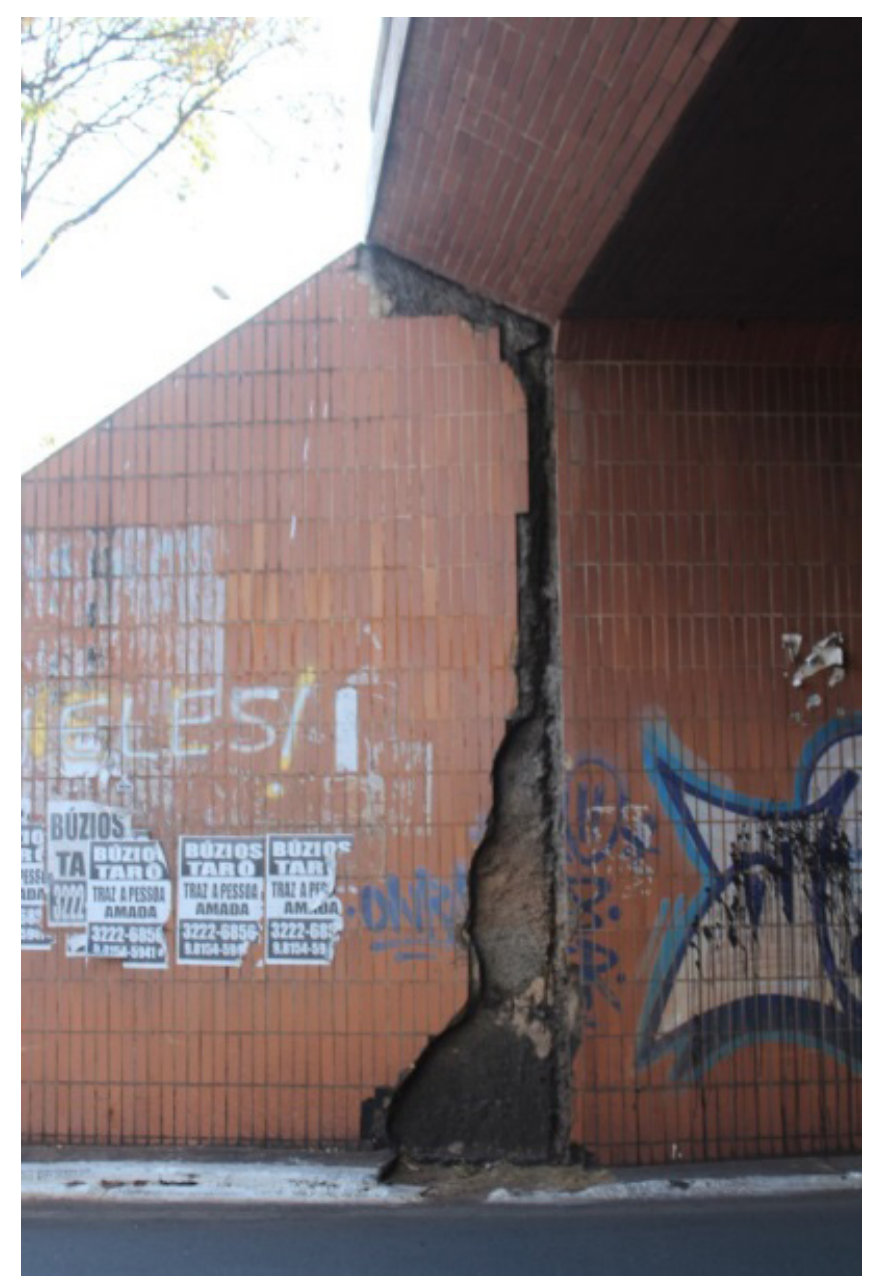

Fonte: Autor

\section{VIADUTO 13/14}

Na Figura 20 é mostrada a vista frontal do viaduto e na Figura 21 pode-se ver na junta de dilatação uma mancha escura que se assemelha a manchas causadas pela humidade e escoamento da água. Este viaduto está localizado próximo a SQS 113.

Utilizando a metodologia GDE/UnB foi encontrado o valor 75,02 de $G_{d^{\prime}}$ que segundo a metodologia o nível de deterioração é classificado como alto. 
Figura 20: Vista frontal do viaduto.

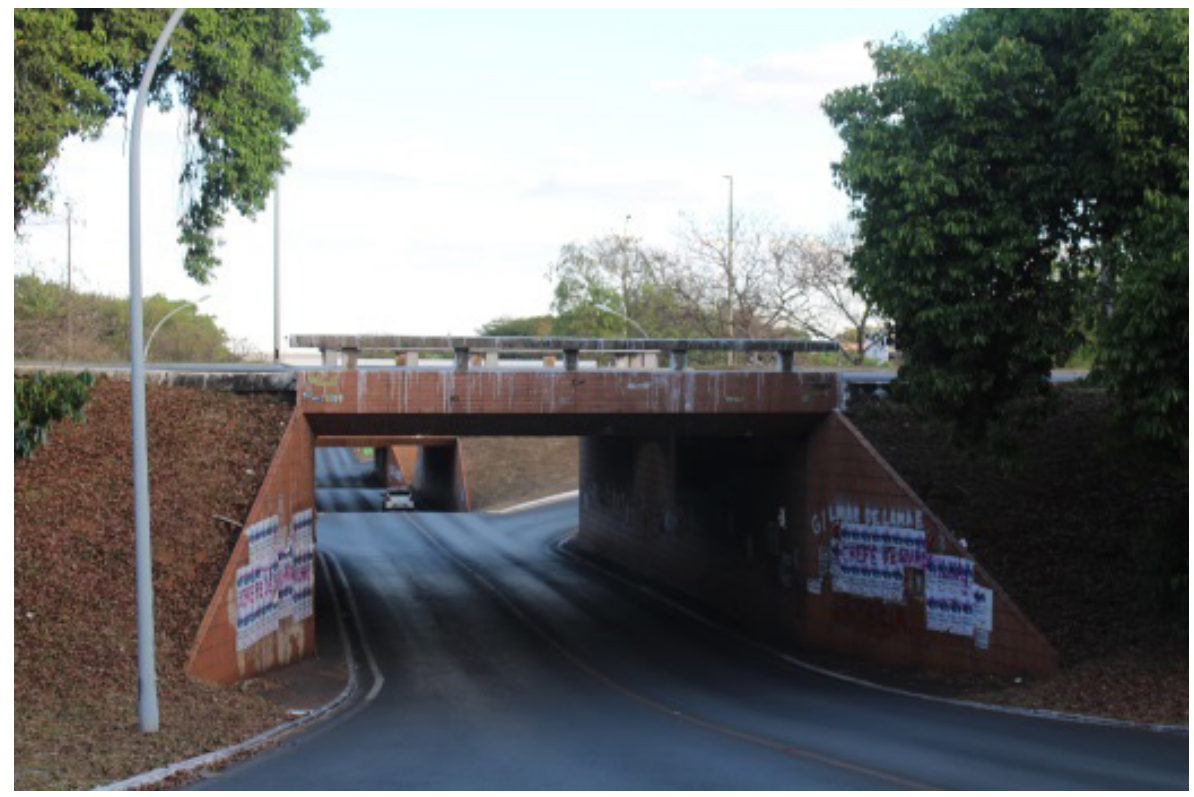

Fonte: Autor

Figura 21: Junta de dilatação com manchas.

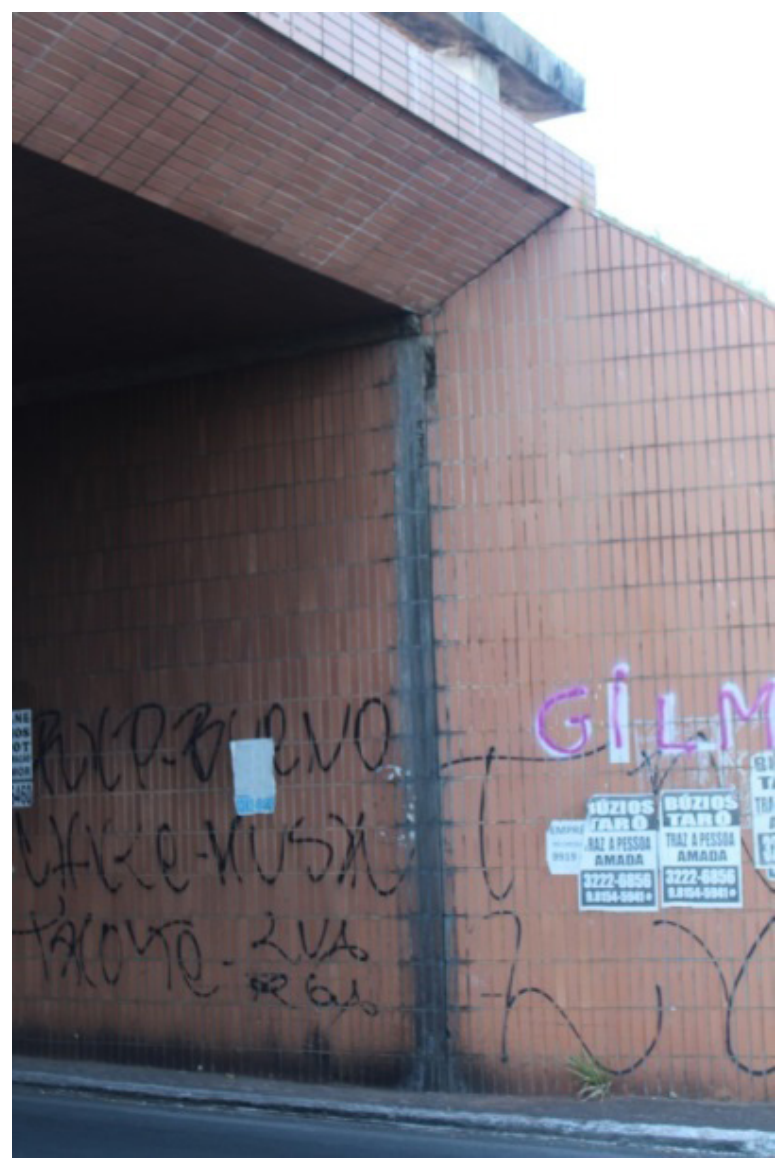

Fonte: Autor 


\section{VIADUTO 15/16}

Na Figura 22 é mostrada a vista frontal do viaduto, na Figura 23 observa-se o desplacamento da laje, na Figura 24 observa-se um buraco ao lado da fundação da cortina sem nenhuma função, onde se acumula água das chuvas, na Figura 25 e Figura 26 é possível ver uma parte do guarda-corpo que foi arrancada. Este viaduto está localizado próximo a SQS 115.

Utilizando a metodologia GDE/UnB foi encontrado o valor 92,11 de $G_{d^{\prime}}$ que segundo a metodologia o nível de deterioração é classificado como sofrível.

Figura 22: Vista frontal do viaduto.

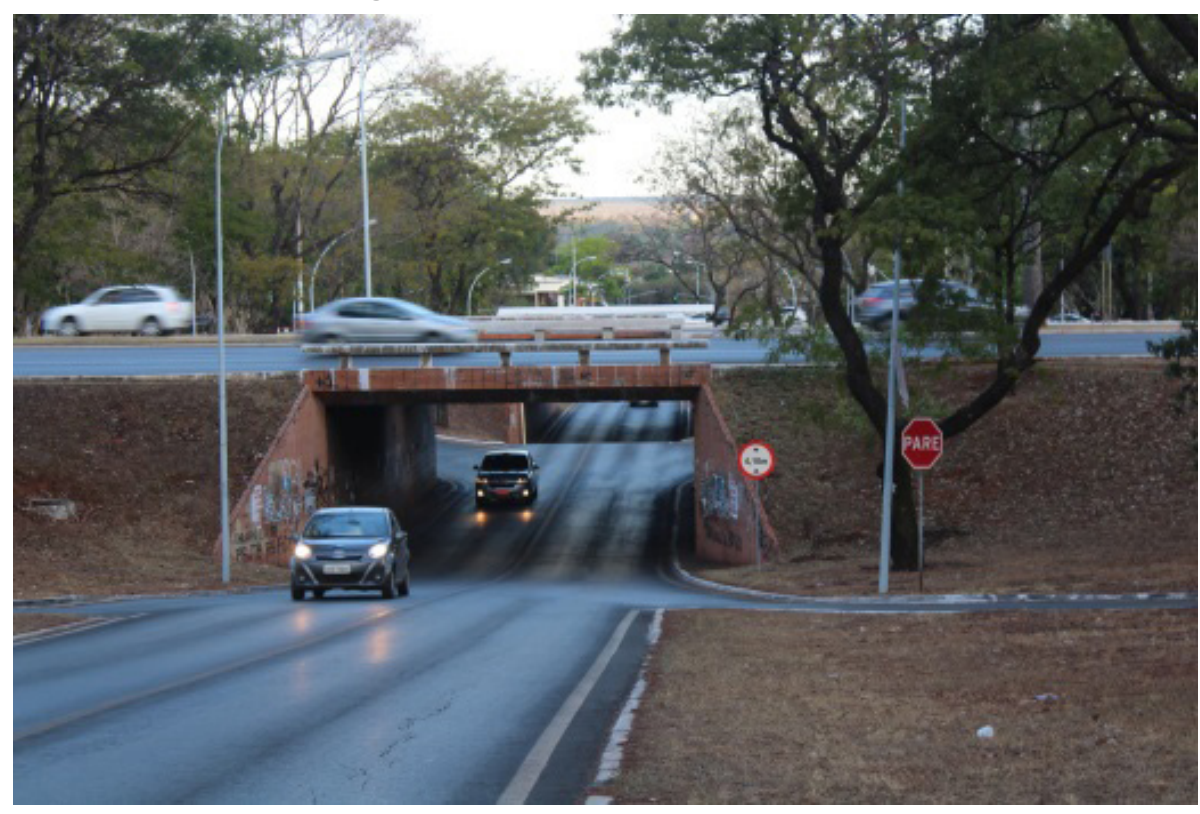

Fonte: Autor

Figura 23: Desplacamento da laje.

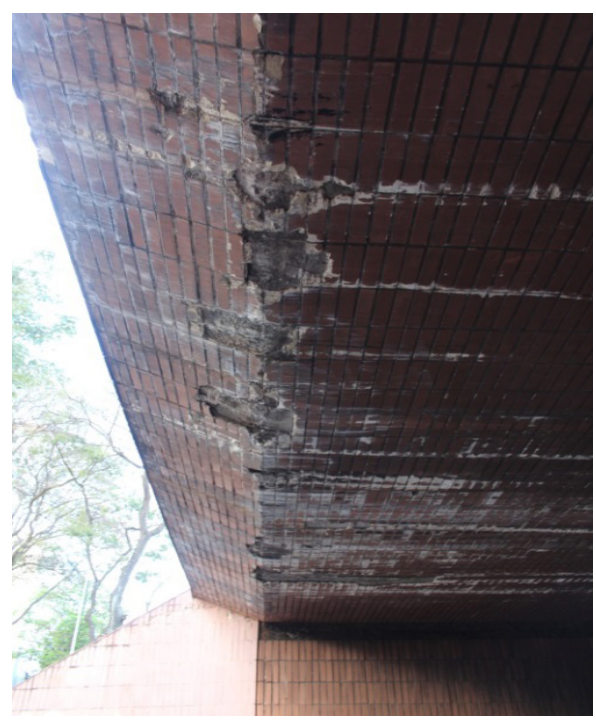

Fonte: Autor

\section{INTER/SCIENTIA}

REVISTA INTERSCIENTIA | V. 7 | N. 1 | P. 2-26 | JAN-JUN/2019 
Figura 24: Buraco próximo à fundação da Cortina.

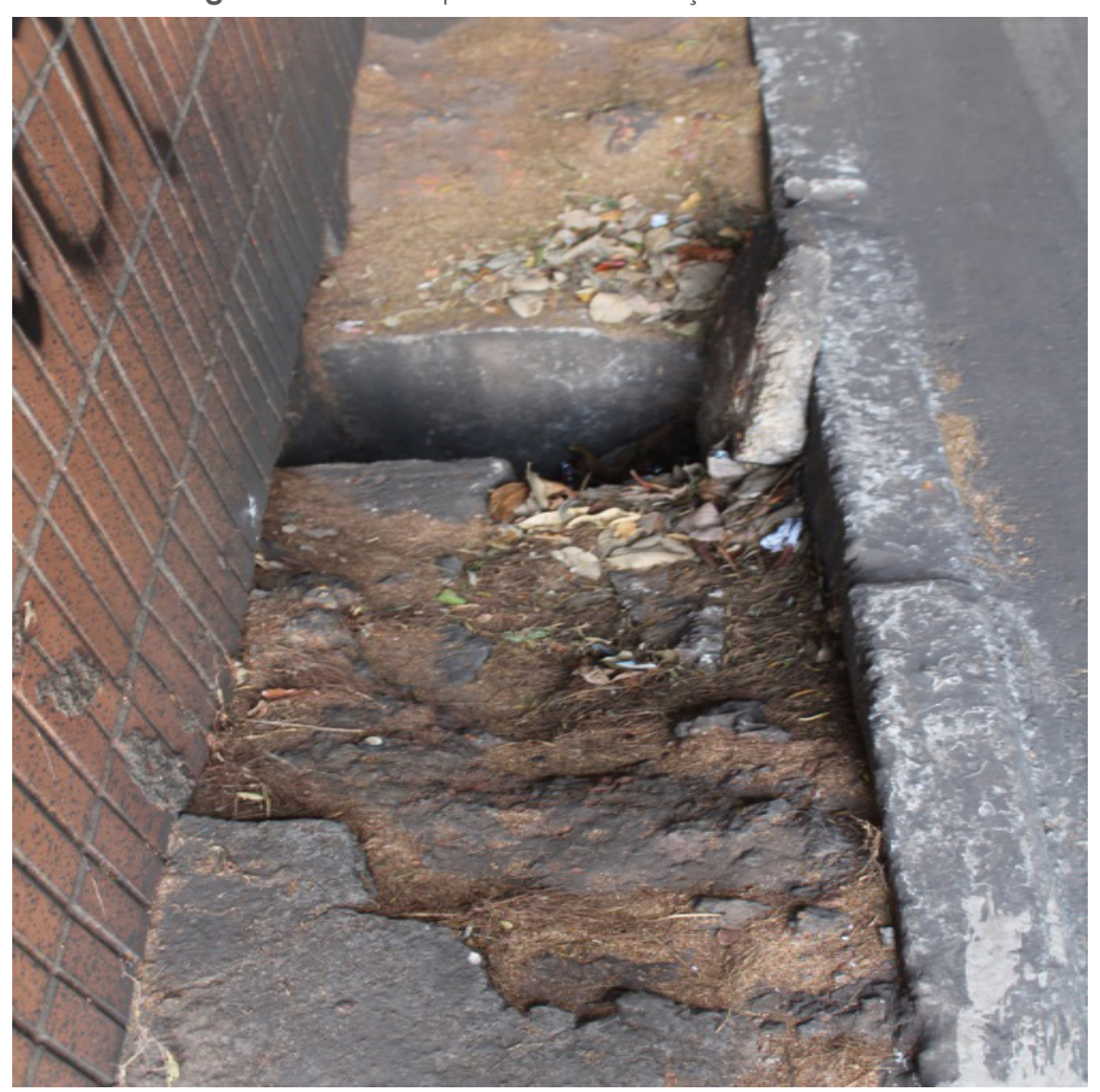

Fonte: Autor

Figura 25: Guarda-corpo.

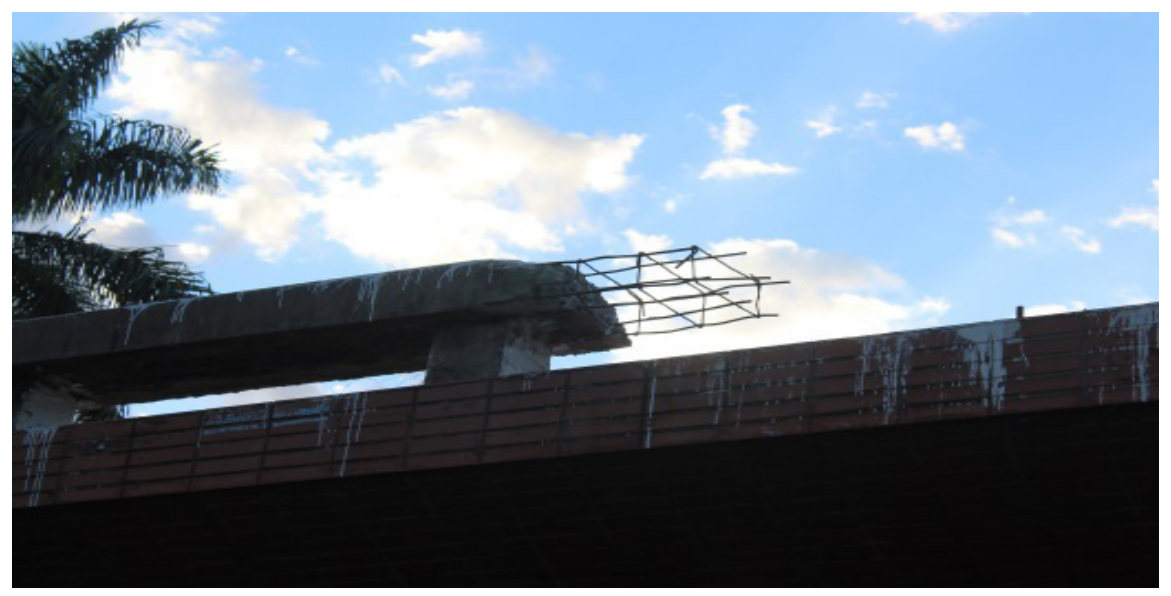

Fonte: Autor 



\begin{tabular}{|c|c|c|c|}
\hline $07 / 08$ & 81,77 & Sofrivel & $\begin{array}{r}\text { Definir prazo para inspeção especializada rigorosa. Planejar } \\
\text { intervenção em curto prazo (máximo 6 meses). }\end{array}$ \\
\hline $09 / 10$ & 49,88 & Médio & $\begin{array}{r}\text { Definir prazo e natureza de nova inspeção. Planejar intervenção em } \\
\text { longo prazo (máximo 2 anos). }\end{array}$ \\
\hline $11 / 12$ & 97,34 & Sofrível & $\begin{array}{r}\text { Definir prazo para inspeção especializada rigorosa. Planejar } \\
\text { intervenção em curto prazo (máximo 6 meses). }\end{array}$ \\
\hline $13 / 14$ & 75,02 & Alto & $\begin{array}{r}\text { Definir prazo para inspeção especializada. Planejar intervenção em } \\
\text { médio prazo (máximo 1 ano). }\end{array}$ \\
\hline $15 / 16$ & 92,11 & Sofrível & $\begin{array}{r}\text { Definir prazo para inspeção especializada rigorosa. Planejar } \\
\text { intervenção em curto prazo (máximo 6 meses). }\end{array}$ \\
\hline
\end{tabular}

\section{CONCLUSÃO}

Por meio da metodologia GDE/UnB é possível retirar dados que fornecem um grande grau de detalhes que servem para a tomada de subsídios dos responsáveis pelas estruturas.

Conforme mostrado estruturas que apresentam o maior nível de degradação são os guarda-corpos, e o elemento com o menor grau de deterioração são as pistas de rolamento. As pistas de rolamento que geram um maior desconforto ao usuário passam por manutenções periódicas gerando um falso diagnóstico e encobrindo os problemas mais graves.

Por meio dos resultados é possível concluir que mais da metade dos viadutos se encontram em um estado de degradação elevado, necessitando de inspeções rigorosas e intervenções em curto prazo, a fim de evitar maiores problemas aos usuários e evitar o acidente como ocorreu com o viaduto na área central de Brasília.

\section{REFERÊNCIAS}

ASSOCIAÇÃO BRASILEIRA DE NORMAS TÉCNICAS ABNT: NBR 15575-1 Edificações habitacionais - Desempenho - Parte 1: requisitos gerais, 2013.

ASSOCIAÇÃO BRASILEIRA DE NORMAS TÉCNICAS ABNT: NBR 5674 Manutenção de edificações-procedimento, 1999.

AMORIM, A. A. Durabilidade das estruturas de concreto armado aparentes, Dissertação de Mestrado, Universidade Federal de Minas Gerais, 2008.

CASTRO, E. K. Desenvolvimento de metodologia para manutenção de estruturas de concreto armado, Dissertação de Mestrado, Departamento de Engenharia Civil, Universidade de Brasília, Brasília, DF, 1994.

EUQUERES, P.: Metodologia de inspeção em estruturas de pontes de concreto armado. Dissertação Mestrado, Universidade Federal de Goiás, Goiânia, 2011. 
FONSECA, R. P.: A estrutura do Instituto Central de Ciências: Aspectos históricos, científicos e tecnológicos de projeto, execução, intervenções e propostas de manutenção. Dissertação de Mestrado em Estruturas e Construção Civil, Departamento de Engenharia Civil e Ambiental, Universidade de Brasília, Brasília, DF, 2007.

HELENE, P. e LEVY, S. Cura do concreto, Boletim técnico 8, 2013.

MARCHETTI, OSVALDEMAR, Pontes de concreto armado, 2008.

MAZER, WELLINGTON. Patologia, Recuperação e reforço de estruturas de concreto, 2008

NOGUEIRA, K., A..Reação álcali-agregado: diretrizes e requisitos da ABNT NBR 15577/2008. Trabalho de conclusão de curso apresentado a Universidade Federal de Minas Gerais, 2010.

POLITO, G. Corrosão em estruturas de concreto armado: causas, mecanismos, prevenção e recuperação. Trabalho de conclusão de curso apresentado a Universidade Federal de Minas Gerais, 2006.

RIBEIRO, R. S.: Análise de manifestações patológicas do concreto em viadutos urbanos Estudo de Caso: Viadutos localizados na Avenida Eixão Norte, 2016.

RODRIGUES, RUI MANUEL, GESTÃO DE EDIFÍCIOS, 2001.

ROSCOE, M, T. Patologias em revestimento cerâmico de fachada. Trabalho de conclusão de curso apresentado a Universidade Federal de Minas Gerais, 2008.

VERLY, R. C. (2015). Avaliação de metodologias de inspeção como instrumento de priorização de intervenções em obras de arte especiais. Dissertação de Mestrado em Estruturas e Construção Civil, Publicação E.DM-015A/15, Departamento de Engenharia Civil e Ambiental, Universidade de Brasília, Brasília, DF,178p.

Recebido em: 17/12/2018.

Aceito em: 14/02/2019. 